\title{
Multilocus genotyping of Giardia duodenalis (Lambl, 1859) from symptomatic human infections in Slovenia
}

\author{
Barbara Šoba $^{1}$, Sabina Islamović ${ }^{1}$, Miha Skvarč $^{1}$ and Simone M. Cacciò ${ }^{2}$ \\ ${ }^{1}$ Institute of Microbiology and Immunology, Faculty of Medicine, University of Ljubljana, Ljubljana, Slovenia; \\ ${ }^{2}$ Department of Infectious, Parasitic and Immunomediated Diseases, Istituto Superiore di Sanità, Rome, Italy
}

\begin{abstract}
Giardiasis is a common gastrointestinal infection of humans and animals with a worldwide distribution. Eight genetic groups (known as assemblages A to $\mathrm{H}$ ) are currently recognised within the species complex of Giardia duodenalis (Lambl, 1859), of which assemblages A and B are responsible for infection of humans and other mammalian hosts. Genotyping data on giardiasis are not available from Slovenia. In this work, we have characterised isolates of G. duodenalis from 85 human symptomatic cases collected during 2002-2013. Genomic DNAs were first tested by a real-time (rt) PCR assay and then by conventional PCR at three loci (beta-giardin, $b g$; triose phosphate isomerase, $t p i$; and glutamate dehydrogenase, $g d h)$. We found that the threshold cycle (Ct) values in rt-PCR testing were higher for samples collected during 2002-2005 and that this was paralleled by a low amplification rate in conventional PCR (6 of 32, i.e. 19\%). In contrast, lower $\mathrm{Ct}$ values and higher amplification rate (45 of 53; 85\%) were observed for samples collected during 2006-2013, suggesting an adverse effect of prolonged freezing of stools. Assemblages A and B were found with an almost identical frequency in the 51 genotyped samples. In agreement with previous studies, sequences from assemblage B isolates were characterised by larger genetic variability and by the presence of heterogeneous positions, which made assignment to specific genotypes difficult. Less variability was observed in sequences from assemblage A isolates, which belonged to the human-specific subassemblage AII. These data showed that the genotypes of $G$. duodenalis that circulate in humans in Slovenia are similar to those previously identified in Europe.
\end{abstract}

Keywords: giardiasis, molecular typing, assemblages, genotypes, epidemiology

The flagellated protist Giardia duodenalis (Lambl, 1859) (syn. G. intestinalis, G. lamblia) is a common gastrointestinal parasite of humans and other mammals, including pets and livestock (Feng and Xiao 2011). A considerable amount of data have shown that $G$. duodenalis is a species complex, whose members show little morphological variation, yet at least eight distinct genetic groups or assemblages (A to $\mathrm{H}$ ) have been recognised based on protein or DNA sequence polymorphisms (Andrews et al. 1989, Monis et al. 2003, Ryan and Cacciò 2013).

The genetic distances separating the assemblages are very big and recent comparisons at the whole genome level (Frantzen et al. 2009, Jerlstrom-Hultqvist et al. 2013) strongly supported that assemblages A, B and E (the three assemblages for which genome sequences are currently available) represent distinct species. The same concept was raised before based on other biological and phenotypic features and the names $G$. duodenalis (assemblage A) and $G$. enterica (assemblage B) were proposed but not widely accepted (Monis et al. 2009).

The epidemiology of giardiasis is complex and multiple transmission routes contribute to human infection, with an important role played by water (Feng and Xiao 2011). Despite many investigations, several important epidemiological aspects remain unclear, including the role of animals in zoonotic transmission (Ryan and Cacciò 2013) and the clinical significance of single and mixed infections with assemblages A and B (Kohli et al. 2008).

To date, no genetic information is available on human giardiasis in Slovenia. Therefore, the aim of the present work was to characterise isolates collected in this country using established molecular methods.

\section{MATERIALS AND METHODS}

Sources of isolates. Stool samples from 85 sporadic, symptomatic human cases of giardiasis throughout Slovenia were referred to the Institute of Microbiology and Immunology (IMI) in Ljubljana between 2002 and 2013. The geographical distribution of cases included in the study is shown in Fig. 1. The mean age of the patients was 31.5 years (range $2-63$ years, $\mathrm{SD}=13$ ), with 51 being males and 34 females.

Cysts of Giardia spp. were identified microscopically in stool smears using a direct immunofluorescence test (MeriFluor, Meridian Bioscience, Cincinnati, Ohio, USA), following the manu-

Address for correspondence: S.M. Cacciò, Department of Infectious, Parasitic and Immunomediated Diseases, Istituto Superiore di Sanità, Viale Regina Elena, 299, Rome 00161, Italy. Phone: +39 064990 3016; Fax +39 064990 3561; E-mail: simone.caccio@iss.it 


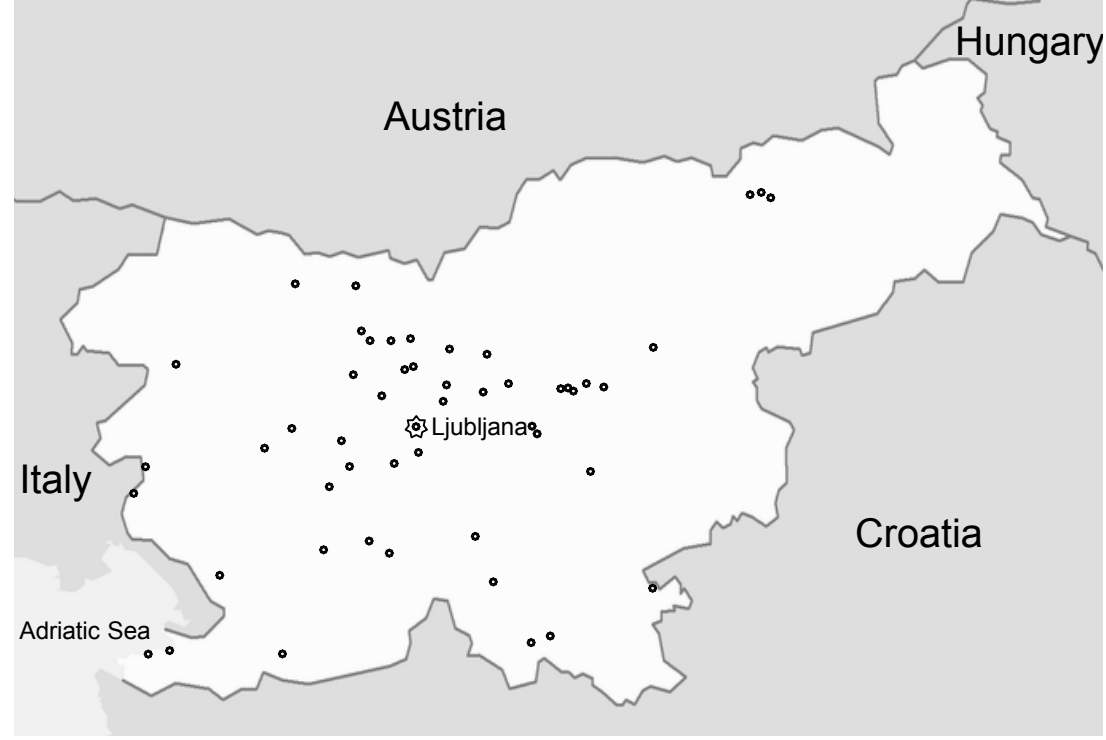

Fig. 1. Map of Slovenia. Dots indicate the geographic origin of the human cases of giardiasis included in the study.

facturer's instructions. Cyst-containing stool samples were stored at $-20^{\circ} \mathrm{C}$ until used for molecular analysis. Positive stool samples were archived as a part of the laboratory collection. Forty-seven stools $(55 \%)$ were also examined for other potential etiological agents of gastroenteritis, including bacteria ( $54 \%$ of stools) and viruses (12\% of stools). Five cases of mixed infection of Giardia and bacteria (Providencia alcalifaciens, Salmonella sp., Campylobacter coli, Shigella boydii and Shigella sonneii), as well as one case of mixed infection of Giardia with rotavirus, were observed.

Molecular analysis. Genomic DNA was extracted from stool samples using either the QIAamp DNA Stool Mini Kit (Qiagen, Hilden, Germany), with an initial incubation of $10 \mathrm{~min}$ at $99^{\circ} \mathrm{C}$, or the FastDNA SPIN Kit for faeces (MP Biomedicals, Solon, Ohio, USA). When extracting DNA by the FastDNA SPIN Kit for faeces, the TissueLyser LT (Qiagen), set at $50 \mathrm{~Hz}$ for $5 \mathrm{~min}$, was used instead of the FastPrep-24 instrument for sample homogenisation. The DNA extracts were stored at $-20^{\circ} \mathrm{C}$ until analysis. DNA from axenic cultures of strains of Giardia duodenalis of assemblage A (WB, genotype AI) and assemblage B (GS, genotype $\mathrm{BIV})$ were used as controls in both real-time (rt) and conventional PCR assays.

All genomic DNAs were first tested using a TaqMan rt-PCR assay (Verweij et al. 2004), which targets a 62-base pair fragment of the small subunit ribosomal (SSU rRNA) gene of $G$. duodenalis. Next, conventional, nested PCR assays were used to amplify fragments of the $b g(511 \mathrm{bp})$, tpi (530 bp) and $g d h(530 \mathrm{bp})$ genes of human isolates of $G$. duodenalis according to published protocols (Sulaiman et al. 2003, Lalle et al. 2005, Cacciò et al. 2008). PCR products were purified using spin columns (QiaQuick PCR Purification kit - Qiagen) and sequenced from both strands. The sequences were edited using CLC Main Workbench 6.0 (CLC bio - Qiagen) and compared to all available sequences using BLAST. Novel sequences without heterogeneous positions have been deposited in the European Molecular Biology Laboratory (EMBL) database under the accession numbers LN626343-LN626354.

Phylogenetic analysis. Multiple alignments were generated using Clustal X (Larkin et al. 2007). For phylogenetic analyses, unambiguous sequences (i.e. sequences not containing heteroge- neous positions) from the current investigation, from a previous study (Cacciò et al. 2008) and from representative sequences retrieved from GenBank were used. The sequences from the three loci were concatenated and phylogenetic trees were inferred by Neighbour-Joining (NJ) or Maximum Likelihood (ML) methods using the Kimura 2 parameter algorithm, as implemented in the software MEGA version 5.4 (Tamura et al. 2011). The robustness of the nodes was tested by a bootstrap analysis of 1000 iterations.

\section{RESULTS}

Using a SSU rRNA rt-PCR assay, all isolates of $G$. $d u$ odenalis $(\mathrm{n}=85)$ yielded positive results. It was noticed, however, that the average threshold cycle $(\mathrm{Ct})$ value of DNAs from samples collected between 2002 and 2005, and stored at $-20^{\circ} \mathrm{C}$ for $8-11$ years before extraction, was 31.1 (range 25.6-36.0), compared to an average $\mathrm{Ct}$ value of 26.6 (range 18.6-38.4) for samples collected between 2006 and 2013, which were stored for no longer than 3 years. The difference in $\mathrm{Ct}$ values between the two groups of samples was statistically significant $(\mathrm{p}<0.01)$.

Using conventional nested PCR assays, 51 of the $85 \mathrm{hu}-$ man isolates $(60 \%)$ were amplified at least at one of the three loci tested (Table 1). In agreement with the rt-PCR results, amplification was largely more successful in the 2006-2013 human samples (85\%) than in the 2002-2005 samples $(19 \%)$.

BLAST comparison with homologous sequences from the GenBank database identified assemblage A in 26/51 (51\%) isolates and assemblage $\mathrm{B}$ in 25/51 (49\%). Assemblage A infections were observed in 9 females and 17 males, whereas assemblage B infections were found in 12 females and 13 males. The distribution of assemblage A and B in females versus males did not differ significantly. No discordant assignment to assemblages was observed for the 45 isolates that could be genotyped at more than one locus (Table 1).

At the $b g$ locus, 49 of 85 (58\%) isolates were PCR positive and sequence analysis showed Assemblage $\mathrm{A}$ in 25 
Table 1. Genotypes of human isolates of Giardia duodenalis (Lambl, 1859) identified at the $b g$, tpi and $g d h$ loci.

\begin{tabular}{|c|c|c|c|c|c|c|}
\hline Isolate & Age & Gender & $b g$ & tpi & $g d h$ & $\begin{array}{l}\text { Assemblage/ } \\
\text { MLG }\end{array}$ \\
\hline Slo1 & 37 & $M$ & neg & $\mathrm{A} 2$ & neg & $\mathrm{A}$ \\
\hline Slo6 & 38 & M & A3 & neg & neg & A \\
\hline Slo9 & 31 & M & A3 & neg & neg & A \\
\hline Slo15 & 23 & $\mathrm{~F}$ & $\mathrm{~B}^{\mathrm{b}}$ & $\mathrm{B}$ & neg & B \\
\hline Slo16 & 36 & M & $\mathrm{B}^{\mathrm{a}}$ & B & neg & B \\
\hline Slo19 & 23 & M & $\mathrm{B}^{\mathrm{b}}$ & neg & neg & B \\
\hline Slo33 & 10 & M & $\mathrm{B}^{\mathrm{b}}$ & $\mathrm{B}^{\mathrm{b}}$ & neg & B \\
\hline Slo34 & 39 & M & $\mathrm{A} 2$ & $\mathrm{~A} 2$ & neg & A \\
\hline Slo35 & 15 & $\mathrm{~F}$ & A3 & $\mathrm{A} 2$ & A4 & AII-4 \\
\hline Slo37 & 24 & M & $\mathrm{A} 2$ & $\mathrm{~A} 2$ & $\mathrm{~A} 2$ & AII-1 \\
\hline Slo38 & 8 & $\mathrm{~F}$ & B & B & B & BIV \\
\hline Slo39 & 36 & M & $\mathrm{A}^{\mathrm{a}}$ & $\mathrm{A} 2$ & A4 & AII \\
\hline Slo40 & 34 & $\mathrm{~F}$ & B & B & B & BIV \\
\hline Slo41 & 33 & $\mathrm{~F}$ & B & neg & neg & B \\
\hline Slo42 & 49 & M & $\mathrm{A} 2$ & $\mathrm{~A} 2$ & $\mathrm{~A} 2$ & AII-1 \\
\hline Slo43 & 37 & M & A3 & $\mathrm{A} 2$ & A2 & AII-2 \\
\hline Slo44 & 30 & $\mathrm{~F}$ & A3 & $\mathrm{A} 2$ & $\mathrm{~A} 2$ & AII-2 \\
\hline Slo45 & 63 & M & A3 & $\mathrm{A} 2$ & A4 & AII-4 \\
\hline Slo47 & 47 & $\mathrm{~F}$ & $\mathrm{~B}^{\mathrm{b}}$ & $\mathrm{B}^{\mathrm{b}}$ & neg & B \\
\hline Slo48 & 36 & M & B & B & $\mathrm{B}$ & BIV \\
\hline Slo49 & 29 & M & $\mathrm{A} 2$ & $\mathrm{~A} 2$ & $\mathrm{~A} 2$ & AII-1 \\
\hline Slo50 & 28 & M & neg & B & neg & B \\
\hline Slo52 & 25 & $\mathrm{~F}$ & A3 & $\mathrm{A} 2$ & A2 & AII-2 \\
\hline Slo53 & 35 & M & $\mathrm{B}^{\mathrm{a}}$ & $\mathrm{B}^{\mathrm{a}}$ & $\mathrm{B}^{\mathrm{b}}$ & B \\
\hline Slo54 & 29 & M & $\mathrm{A} 2$ & $\mathrm{~A} 2$ & $\mathrm{~A} 2$ & AII-1 \\
\hline Slo55 & 26 & M & $\mathrm{B}^{\mathrm{b}}$ & $\mathrm{B}^{\mathrm{b}}$ & $\mathrm{B}^{\mathrm{a}}$ & B \\
\hline Slo56 & 33 & $\mathrm{~F}$ & A3 & $\mathrm{A} 2$ & $\mathrm{~A} 2$ & AII-2 \\
\hline Slo58 & 33 & $\mathrm{~F}$ & $\mathrm{~A} 2$ & $\mathrm{~A}^{\mathrm{c}}$ & $\mathrm{A} 2$ & AII \\
\hline Slo59 & 39 & M & A3 & $\mathrm{A} 2$ & A4 & AII-4 \\
\hline Slo60 & 38 & M & A3 & $\mathrm{A} 2$ & $\mathrm{~A} 2$ & AII-2 \\
\hline Slo61 & 21 & M & B & $\mathrm{B}^{\mathrm{a}}$ & $\mathrm{B}^{\mathrm{a}}$ & B \\
\hline Slo62 & 52 & $\mathrm{~F}$ & A3 & $\mathrm{A} 2$ & $\mathrm{~A} 2$ & AII-2 \\
\hline Slo63 & 42 & M & B & B & B & BIV \\
\hline Slo64 & 11 & $\mathrm{~F}$ & A3 & $\mathrm{A} 2$ & A4 & AII-4 \\
\hline Slo65 & 2 & M & A3 & $\mathrm{A} 2$ & A4 & AII-4 \\
\hline Slo67 & 31 & $\mathrm{~F}$ & $\mathrm{~B}^{\mathrm{a}}$ & $\mathrm{B}^{\mathrm{a}}$ & $\mathrm{B}^{\mathrm{a}}$ & B \\
\hline Slo68 & 31 & $\mathrm{~F}$ & A3 & $\mathrm{A} 2$ & A4 & AII-4 \\
\hline Slo69 & 45 & $\mathrm{~F}$ & $\mathrm{~A} 2$ & $\mathrm{~A} 2$ & A4 & AII \\
\hline Slo70 & 23 & M & B & B & $\mathrm{B}^{\mathrm{a}}$ & B \\
\hline Slo71 & 31 & M & $\mathrm{A} 2$ & $\mathrm{~A} 2$ & A3 & AII-3 \\
\hline Slo72 & 58 & $\mathrm{~F}$ & $\mathrm{~B}^{\mathrm{a}}$ & $\mathrm{B}^{\mathrm{b}}$ & $\mathrm{B}^{\mathrm{a}}$ & B \\
\hline Slo73 & 26 & M & $\mathrm{B}^{\mathrm{a}}$ & $\mathrm{B}^{\mathrm{a}}$ & $\mathrm{B}^{\mathrm{a}}$ & B \\
\hline Slo75 & 58 & M & $\mathrm{A} 2$ & $\mathrm{~A} 2$ & A4 & AII \\
\hline Slo76 & 9 & $\mathrm{~F}$ & $\mathrm{~B}^{\mathrm{b}}$ & B & B & BIV \\
\hline Slo77 & 33 & M & B & B & $\mathrm{B}^{\mathrm{a}}$ & B \\
\hline Slo79 & 47 & $\mathrm{~F}$ & $\mathrm{~B}^{\mathrm{a}}$ & $\mathrm{B}^{\mathrm{a}}$ & $\mathrm{B}^{\mathrm{a}}$ & B \\
\hline Slo80 & 47 & $\mathrm{~F}$ & $\mathrm{~B}^{\mathrm{a}}$ & $\mathrm{B}^{\mathrm{a}}$ & $\mathrm{B}^{\mathrm{a}}$ & B \\
\hline Slo81 & 35 & $\mathrm{~F}$ & $\mathrm{~B}^{\mathrm{a}}$ & $\mathrm{B}^{\mathrm{b}}$ & $\mathrm{B}^{\mathrm{b}}$ & B \\
\hline Slo82 & 31 & $\mathrm{~F}$ & $\mathrm{~B}^{\mathrm{a}}$ & $\mathrm{B}^{\mathrm{a}}$ & $\mathrm{B}^{\mathrm{a}}$ & B \\
\hline Slo83 & 29 & M & B & B & B & BIV \\
\hline Slo85 & 27 & M & A3 & $\mathrm{A}^{\mathrm{c}}$ & A 2 & AII \\
\hline
\end{tabular}

MLG - Multi-locus genotypes; ${ }^{a}$ sequences showing heterogeneous positions; ${ }^{\mathrm{b}}$ new variants without heterogeneous positions; ${ }^{\mathrm{c}}$ single SNP difference from genotype A2

(51\%) isolates and assemblage B in $24(49 \%)$ isolates. Among assemblage A isolates, 9 were identical to genotype A2 (AY072723) and 15 were identical to genotype A3 (AY072724). A single isolate had a sequence identical to genotype A2 except for a single heterogeneous position (C261Y). Among assemblage B isolates, sequences from 9 of $24(38 \%)$ isolates showed heterogeneous positions and

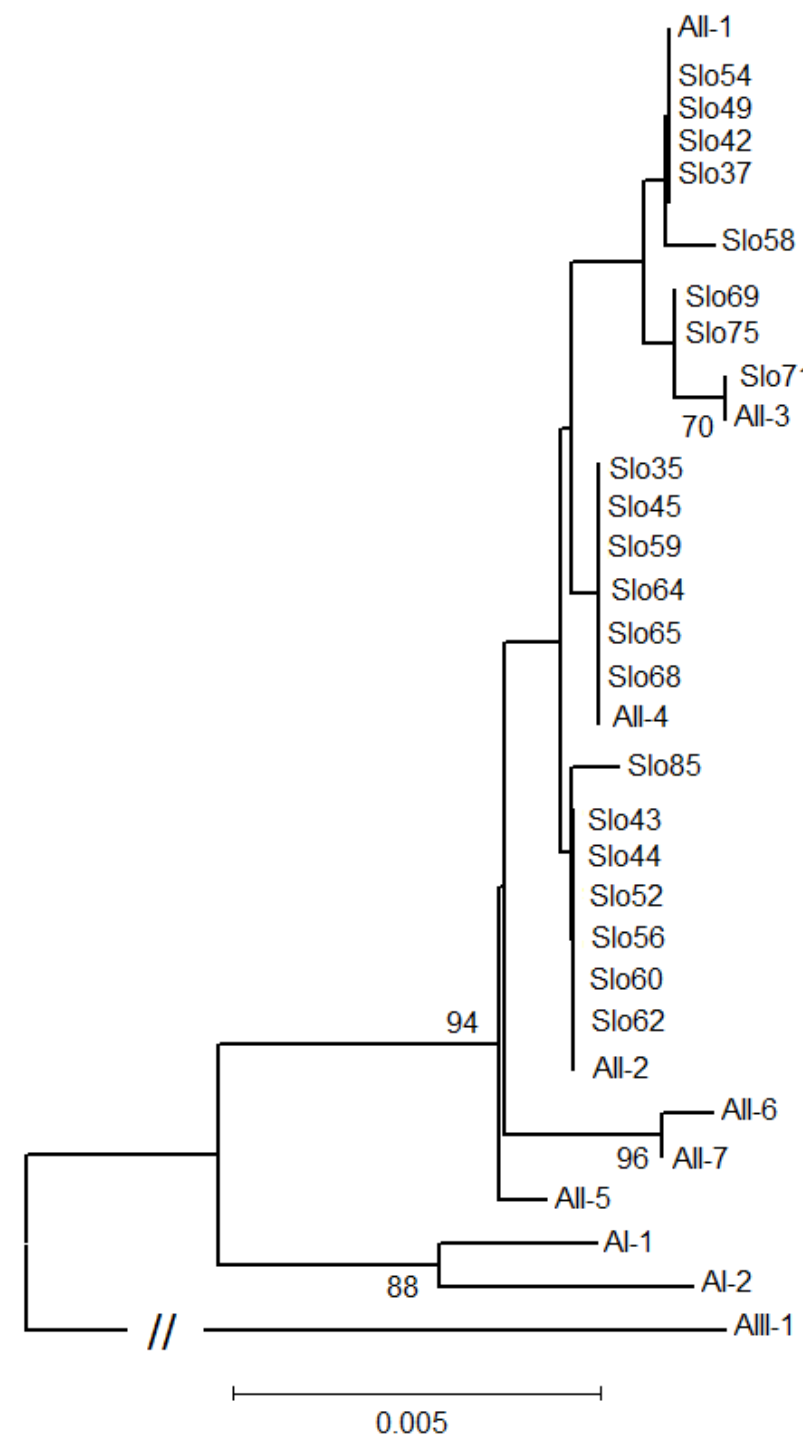

Fig. 2. Neighbour Joining phylogenetic tree of concatenated $b g$, tpi and $g d h$ genes from assemblage A isolates. Multi-locus genotypes from a previous study (Cacciò et al. 2008) are indicated. Only bootstrap support values $>50 \%$ are shown.

could not be unequivocally assigned to a specific genotype, whereas no heterogeneous positions were observed in the remaining 15 isolates. Among the latter, six new variants were detected (Table 1).

At the tpi locus, 47 of 85 (55\%) isolates were PCR positive and sequence analysis show assemblages $\mathrm{A}$ and $\mathrm{B}$ in $24(51 \%)$ and $23(49 \%)$ isolates, respectively. Among assemblage A, genotype A2 (U57897) was found in 22 isolates, whereas two isolates differed from genotype A2 by a single nucleotide polymorphism (SNP) at position 445 (G445A). There was no evidence of heterogeneous positions among assemblage A isolates. Among assemblage B isolates, sequences of 7 of $23(30 \%)$ isolates showed heterogeneous positions, whereas no heterogeneous positions were observed in the remaining 16 isolates. Among the latter, five new variants were detected (Table 1).

At the $g d h$ locus, 40 of 85 (47\%) samples were PCR positive and sequence analysis showed assemblage $\mathrm{A}$ in 55\% (22/40) and assemblage B in $45 \%$ (18/40) of the 


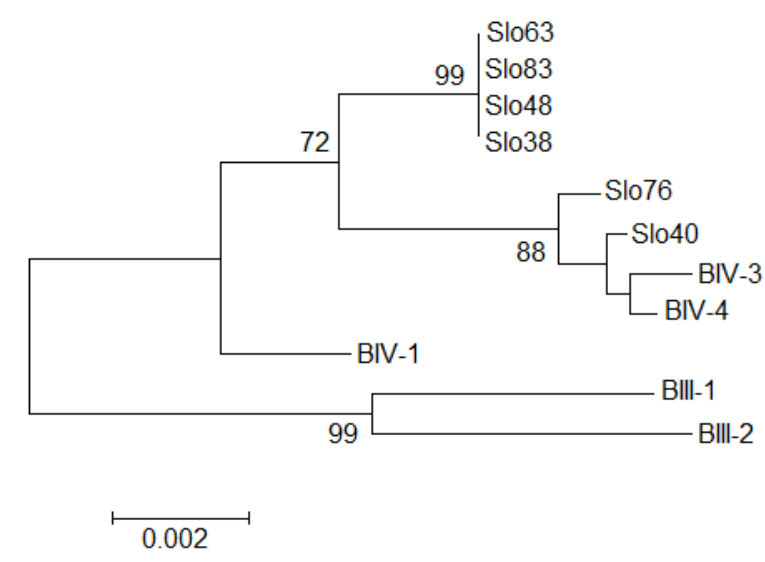

Fig. 3. Neighbour Joining phylogenetic tree of concatenated $b g$, tpi and $g d h$ genes from assemblage B isolates. Multi-locus genotypes from a previous study (Cacciò et al. 2008) are indicated. Only bootstrap support values $>50 \%$ are shown.

isolates. Among assemblage A isolates, 12 were identical to genotype A2 (AY178736), 9 were identical to genotype A4 (EF507657), and one was identical to genotype A3 (EU278608). Among assemblage B isolates, 10 of 18 $(56 \%)$ sequences showed heterogeneous positions, whereas no heterogeneous positions were observed in the remaining eight isolates. Among the latter, two new variants were detected (Table 1).

Sequence data were generated from the three loci for 40 of $85(47 \%)$ human isolates (Table 1). A phylogenetic analysis of the concatenated $b g, t p i$ and $g d h$ sequences from assemblage A (Fig. 2) showed that the so-defined Multi-locus genotypes (MLGs) from Slovenian isolates corresponded, or were very closely related, to previously described in human isolates from Europe, namely to MLG AII-1, MLG AII-2, MLG AII-3 and MLG AII-4. Among assemblage B isolates, phylogenetic analysis of MLGs was performed only for the six isolates that had sequences without heterogeneous positions; this showed that MLGs from Slovenia grouped with isolates from subassemblage BIV (Fig. 3).

\section{DISCUSSION}

The main goal of this study was to characterise at the molecular level human isolates of Giardia duodenalis collected in Slovenia, a European country for which no such data were previously available. Giardiasis is included in the list of notifiable diseases in independent Slovenia since 1991, and cases are reported to the European Centre for Disease Control. In 2011, the crude incidence rate of giardiasis in Slovenia was estimated at 1.51 per 100000 population, which is lower than the average European value of 5.49 (European Centre for Disease Prevention and Control 2013). These data, however, should be interpreted with caution, as giardiasis is likely to be underdiagnosed and under-reported in most European countries, including Slovenia. According to the information from the National Institute of Public Health (NIJZ) of the Republic of Slovenia, no epidemics, foodborne or waterborne outbreaks of giardiasis have been reported during the course of this study. However, cysts of Giardia have been detected in several water supplies, though a link to human disease has not been established so far (Gorazd Pretnar and Matjaž Retelj, National Laboratory of Health, Environment and Food, Slovenia - pers. comm.). Since rural areas represent a significant part of the Slovenian territory and livestock farming is one of the most important agricultural activities, a role of livestock in the environmental contamination and transmission of zoonotic diseases is to be considered.

In this study, stool samples from 85 sporadic human cases of giardiasis collected between 2002 and 2013 were analysed. It is noteworthy that most cases are from adults (mean age, 31.5 years), and that children are underrepresented (only five cases were $0-10$ years old). This seems to contrast with the fact that giardiasis is mostly a paediatric infection worldwide (Cacciò and Sprong 2011). In Europe, the highest notification rate was in $0-4$ year old male children, with 11.2 per 100000 population, followed by $0-4$ year old female children, with 9.8 per 100000 population (European Centre for Disease Prevention and Control 2013). However, according to the information from NIJZ, in Slovenia only $5.1 \%$ and $13.4 \%$ of all cases reported in the last 9 years were from children $0-4$ and $0-14$ years old, respectively.

Genotyping of 51 human samples showed assemblages $\mathrm{A}$ and $\mathrm{B}$ with almost identical frequencies. For the 45 isolates typed at more than one locus, assignment to assemblages was always concordant, indicating an apparent absence of inter-assemblage recombination or of mixed infections in the parasite circulating in Slovenia. Phylogenetic analysis of MLGs, performed on concatenated sequences with no detectable heterogeneity, showed that 21 assemblage A isolates from Slovenia clustered with other human-derived MLGs, all belonging to subassemblage AII (Fig. 2). The same analysis on assemblage B isolates showed clustering of six Slovenian isolates with reference sequences from subassemblage BIV (Fig. 3).

The fact that sequencing profiles from assemblage A isolates rarely showed heterogeneity, whereas the opposite characterise sequences from assemblage B isolates, largely agrees with previous studies (Sprong et al. 2009, Feng and Xiao 2011, Ryan and Cacciò 2013). As discussed extensively in the literature, this heterogeneity can be attributed to the presence of different alleles in the nuclei of single cysts or to the presence of genetically different cysts in a mixed infection. As demonstrated by the elegant study of Ankarklev et al. (2012), who genotyped single cysts from clinical samples, both situations occur, even in the parasite population that infects a single individual.

Apart from the underlining mechanism(s), the practical implication of allelic sequence heterozygosity (ASH) is that isolates cannot be assigned to subtypes, making meaningful comparisons with other available data impossible (Cacciò et al. 2008, Lebbad et al. 2010). It has been suggested that sequence analyses of both conserved and variable genes are required to characterise assemblage B isolates (Wielinga et al. 2011), but this is difficult to apply to large number of isolates. In contrast, since ASH is not uniformly distributed in the genome, at least in the GS strain of assemblage B that has been sequenced (Franzen 
et al. 2009), it should be possible to develop new markers by targeting regions of the genome less affected by ASH (Wielinga et al 2015).

The clinical manifestations of giardiasis range from mild intestinal problems that resolve spontaneously in a week to complex symptoms that last up to several weeks, such as chronic diarrhoea, abdominal pain, nausea, weight loss, extra-intestinal manifestations and post-infectious fatigue (Halliez and Buret 2013). A number of investigations have tried to establish a correlation between symptomatology and the presence of either assemblage A or B (or both) in humans. Results from these studies have been controversial, with some claiming a correlation of assemblage A with symptoms, others a correlation of assemblage $\mathrm{B}$ with symptoms, and others no such correlation (Cacciò and Sprong 2011). In this work, assemblages A and B were found with similar frequency in the 51 symptomatic patients genotyped, thus no correlation appears to exist between parasite strains and symptoms in the host.

Another debated aspect is the occurrence of zoonotic transmission of giardiasis (Ryan and Cacciò 2013). As stated above, Slovenia is predominantly rural country and this has prompted a number of studies on zoonotic infections. Among intestinal parasites, a previous study has shown a predominance of the zoonotic species Cryptosporidium parvum Tyzzer, 1912 in humans (see Soba and Logar 2008), and demonstrated that identical parasite subtypes circulate in livestock and humans, thus confirming the zoonotic potential of C. parvum. Rotavirus genotypes of bovine and porcine origin were detected in human infections (Steyer et al. 2008, 2010, 2013a) and, more recently, an orthoreovirus strain with high similarity to viruses detected in European bats was found in a child hospitalised with acute gastroenteritis (Steyer et al. 2013b).

In 2012, a study on Clostridium difficile showed a considerable overlap between ribotypes isolated from humans, animals and the environment, suggesting that pigs, cattle and poultry can be an important and emerging source of human infection or colonisation in Slovenia (Janezic et al. 2012). In contrast with those studies, only the non-zoonotic assemblage E was found in 81 samples from Slovenian cattle by a real-time PCR assay (van Lith et al. 2015), suggesting a less important role of livestock in the transmission of giardiasis. Surveys of other animals will allow drawing more robust conclusions on zoonotic transmission of giardiasis in Slovenia.

However, the present study has some limitations. First, as stated above, the examined cases of human giardiasis were mostly from adults and children were under-represented. Given that carriage of intestinal protists is low in children living in Europe (Guarino et al. 2014), it seems plausible that paediatricians exclude parasites from the diagnostic scheme of gastroenteritis, thus contributing to the underdiagnosis of giardiasis in children. Moreover, giardiasis can occur as a mixed infection with other pathogens with more acute course and can therefore remain undiagnosed. The distribution of $G$. duodenalis assemblages and genotypes in Slovenian children may thus differ from that observed in this study. Second, we found that all 85 DNA from human stools tested positive for DNA of $G$. duodenalis using a TaqMan rt-PCR assay (Verweij et al. 2004), whereas only $51(60 \%)$ resulted positive by conventional, nested PCR assays at three different loci. The rate of positivity, however, was much higher $(85 \%)$ for more recently collected samples than for older one (19\%). This may be explained by more extensive fragmentation of DNA extracted from stools stored for prolonged time at $-20^{\circ} \mathrm{C}$, resulting in a template from which the multi-copy, $62 \mathrm{bp}$ target of rt-PCR, is amplified more efficiently than the single copy, $500 \mathrm{bp}$ targets of conventional PCR.

In conclusion, this study showed that assemblages and genotypes of $G$. duodenalis associated with human giardiasis in Slovenia are those that predominantly circulate in Europe, and confirmed that assemblage B isolates are difficult to genotype.

Acknowledgements. The work was supported by the Slovenian Research Agency (Grant No. P3-0083) and by the Directorate General for Health and Consumer Affairs (DG SANCO) of the European Commission for the year 2014.

\section{REFERENCES}

Andrews R.H., Adams M., Boreham P.F., Mayrhofer G., Meloni B.P. 1989: Giardia intestinalis: electrophoretic evidence for a species complex. Int. J. Parasitol. 19: 183-190.

Ankarklev J., Svard S.G., Lebbad M. 2012: Allelic sequence heterozygosity in single Giardia parasites. BMC Microbiol. 12: 65.

Cacciò S.M., Beck R., Lalle M., Marinculic A., Pozio E. 2008: Multilocus genotyping of Giardia duodenalis reveals striking differences between assemblages A and B. Int. J. Parasitol. 38: 1523-1531.

CACCiÒ S.M., Sprong H. 2011: Epidemiology of human giardiasis. In: H.D. Lujan and S. Svard (Eds.), Giardia: a Model Organism. Springer-Verlag, Wien, pp. 17-28.

European Centre for Disease Prevention and Control 2013: Annual Epidemiological Report reporting on 2011 surveillance data and 2012 epidemic intelligence data. European Centre for Disease Prevention and Control, Stockholm, pp. 76-79.
FEnG Y., XiaO L. 2011: Zoonotic potential and molecular epidemiology of Giardia species and giardiasis. Clin. Microbiol. Rev. 24: $110-140$.

Franzen O., Jerlström-Hultqvist J., Castro E., Sherwood E., Ankarklev J., Reiner D.S., Palm D., Andersson J.O., Andersson B., Svärd S.G. 2009: Draft genome sequencing of Giardia intestinalis assemblage B isolate GS. PLoS Pathog. 5: e1000560.

Guarino A., Ashrenazi S., Gendrel D., Lo Vecchio A., Shamir R., Szajewska H. 2014: European Society for Pediatric Gastroenterology, Hepatology, and Nutrition/European Society for Pediatric Infectious Diseases evidence-based guidelines for the management of acute gastroenteritis in children in Europe: update 2014. J. Pediatr. Gastroenterol. Nutr. 59: 132-152.

Halliez M.C., Buret A.G. 2013: Extra-intestinal and long term consequences of Giardia duodenalis infections. World J. Gastroenterol. 19: 8974-8985. 
JANEZIC S., OCEPEK M., ZIDARIC V., RuPNIK M. 2012: Clostridium difficile genotypes other than ribotype 078 that are prevalent among human, animal and environmental isolates. BMC Microbiol. 12: 48 .

Jerlstrom-Hultqvist J., Ankarklev J., Svard S.G. 2013: Is human giardiasis caused by two different Giardia species? Gut Microbes 1: 379-382.

Kohli A., Bushen O.Y., Pinkerton R.C., Houpt E., Newman R.D., Sears C.L., Lima A.A., Guerrant R.L. 2008: Giardia duodenalis assemblage, clinical presentation and markers of intestinal inflammation in Brazilian children. Trans. R. Soc. Trop. Med. Hyg. 102: 718-725.

Lalle M., Pozio E., Capelli G., Bruschi F., Crotti D., CaCCIÒ S.M. 2005: Genetic heterogeneity at the beta-giardin locus among human and animal isolates of Giardia duodenalis and identification of potentially zoonotic subgenotypes. Int. J. Parasitol. 35: 207-213.

Larkin M.A., Blackshield G., Brown N.P., Chenna R., McGettigan P.A., McWilliam H., Valentin F., Wallace I.M., Wilm A., Lopez R., Thompson J.D., Gibson T.J., HigGINS D.G. 2007: Clustal W and Clustal X version 2.0. Bioinformatics 23: 2947-2948.

Lebbad M., Mattsson J.G., Christensson B., Luungström B., Backhans A., Andersson J.O. Svärd S.G. 2010: From mouse to moose: multilocus genotyping of Giardia isolates from various animal species. Vet. Parasitol. 168: 231-239.

Monis P.T., Andrews R.H., Mayrhofer G., Ey P.L. 2003: Genetic diversity within the morphological species Giardia intestinalis and its relationship to host origin. Infect. Genet. Evol. 3: 29-38.

Monis P.T., Cacciò S.M., Thompson R.C. 2009: Variation in Giardia: towards a taxonomic revision of the genus. Trends Parasitol. 25: 93-100

RyAn U., CACCIÒ S.M. 2013: Zoonotic potential of Giardia. Int. J. Parasitol. 43: 943-956.

Soba B., Logar J. 2008: Genetic classification of Cryptosporidium isolates from humans and calves in Slovenia. Parasitology 135: $1263-1270$.

Sprong H., CaCciò S.M., van Der Giessen J.W. 2009: Identification of zoonotic genotypes of Giardia duodenalis. PLoS Negl. Trop. Dis. 3: e558.

Steyer A., Bajzelj M., Iturriza-Gómara M., Mladenova Z., Korsun N., Poljsak-Prijatelu M. 2010: Molecular analysis of human group A rotavirus G10P[14] genotype in Slovenia. J. Clin. Virol. 49:121-125.
Steyer A., Gutiérrez-Aguire I., Kolenc M., Koren S., Kutnjak D., Pokorn M., Poljšak-Prijatelj M., Racki N., Ravnikar M., Sagadin M., Fratnik Steyer A., Toplak N. 2013b: High similarity of novel orthoreovirus detected in a child hospitalized with acute gastroenteritis to mammalian orthoreoviruses found in bats in Europe. J. Clin. Microbiol. 51: 3818-3825.

Steyer A., Poljsak-Prijatelj M., Barlic-Maganja D., MARIN J. 2008: Human, porcine and bovine rotaviruses in Slovenia: evidence of interspecies transmission and genome reassortment. J. Gen. Virol. 89: 1690-1698.

Steyer A., Sagadin M., Kolenc M., Poljšak-Prijatelu M. 2013a: Whole genome sequence analysis of bovine G6P[11] rotavirus strain found in a child with gastroenteritis. Infect. Genet. Evol. 13: 89-95.

Sulaiman I.M., Fayer R., Bern C., Gilman R.H., Trout J.M., Schantz P.M., Das P., Lal A.A., XiaO L. 2003: Triosephosphate isomerase gene characterization and potential zoonotic transmission of Giardia duodenalis. Emerg. Infect. Dis. 9: 1444-1452.

Tamura K., Peterson D., Peterson N., Stecher G., Nei M., KUMAR S. 2011: MEGA5: molecular evolutionary genetics analysis using maximum likelihood, evolutionary distance, and maximum parsimony methods. Mol. Biol. Evol. 28: 2731-2739.

Van Lith L., Šoba B., Vizcaino V.V., Svard S., Sprong H., Tosini F., Pozio E., CACCiò S.M. 2015: A real-time assemblage-specific PCR assay for the detection of Giardia duodenalis assemblages A, B and E in fecal samples. Vet. Parasitol. 211: $28-34$.

Verweij J.J., Blangé R.A., Templeton K., Schinkel J., BrieNen E.A., van Rooyen M.A., van Lieshout L., Polderman A.M. 2004: Simultaneous detection of Entamoeba histolytica, Giardia lamblia, and Cryptosporidium parvum in fecal samples by using multiplex real-time PCR. J. Clin. Microbiol. 42: 1220-1223.

Wielinga C., Ryan U., Thompson R.C.A., Monis P. 2011: Multi-locus analysis of Giardia duodenalis intra-Assemblage B substitution patterns in cloned culture isolates suggests sub-Assemblage B analyses will require multi-locus genotyping with conserved and variable genes. Int. J. Parasitol. 41: 495-503.

Wielinga C., Thompson R.C.A., Monis P., Ryan U. 2015: Identification of polymorphic genes for use in assemblage B genotyping assays through comparative genomics of multiple assemblage B Giardia duodenalis isolates. Mol. Biochem. Parasitol. 201: $1-4$. 